Meta

Journal des traducteurs

Translators' Journal

\title{
Estudio descriptivo comparado de la variación sinonímica en el lenguaje jurídico inglés y español: implicaciones para la traducción
}

\section{Leticia Moreno-Pérez}

Volume 64, numéro 1, avril 2019

URI : https://id.erudit.org/iderudit/1065337ar

DOI : https://doi.org/10.7202/1065337ar

Aller au sommaire du numéro

Éditeur(s)

Les Presses de l’Université de Montréal

ISSN

0026-0452 (imprimé)

1492-1421 (numérique)

Découvrir la revue

Citer cet article

Moreno-Pérez, L. (2019). Estudio descriptivo comparado de la variación sinonímica en el lenguaje jurídico inglés y español: implicaciones para la traducción. Meta, 64(1), 266-284. https://doi.org/10.7202/1065337ar

\section{Résumé de l'article}

La variation synonymique est un recours habituel dans les langues de spécialité, notamment dans le langage juridique (Acuyo Verdejo 2004 ; Thiry 2009a ; Barceló Martínez 2010). S’agissant d’une stratégie sémantique, une interprétation inexacte peut changer le sens et les relations juridiques créés dans le texte. Par conséquent, une détection et une gestion précise sont essentielles. Cette étude a l'intention d'approfondir dans l'utilisation de la variation synonymique dans le domaine juridique. L'objectif est de comprendre le fonctionnement de ce phénomène dans les deux langues de travail, anglais et espagnol, ce qui permettra établir ressemblances et différences entre elles. L'étude s'effectuera au moyen de l'analyse d'un corpus comparable de contrats de vente dans les deux langues. Afin de détecter les cas de variation synonymique dans les textes, nous utiliserons des marques textuelles pour établir une liste de patrons d'usage mesurant fréquence, productivité, fonctionnement et relation d'équivalence créé entre synonymes. Les résultats contribueront à comprendre comment la variation synonymique pourrait affecter la compréhension et interprétation des textes juridiques, spécifiquement en ce qui concerne la traduction, dans laquelle une gestion appropriée de cette stratégie peut être indispensable pour importer adéquatement le sens du texte source vers le texte cible. 


\title{
Estudio descriptivo comparado de la variación sinonímica en el lenguaje jurídico inglés y español: implicaciones para la traducción
}

\author{
LETICIA MORENO-PÉREZ \\ Universidad de Valladolid, Valladolid, España \\ leticia.morenop@fing.uva.es
}

\section{RÉSUMÉ}

La variation synonymique est un recours habituel dans les langues de spécialité, notamment dans le langage juridique (Acuyo Verdejo 2004; Thiry 2009a; Barceló Martínez 2010). S'agissant d'une stratégie sémantique, une interprétation inexacte peut changer le sens et les relations juridiques créés dans le texte. Par conséquent, une détection et une gestion précise sont essentielles. Cette étude a l'intention d'approfondir dans l'utilisation de la variation synonymique dans le domaine juridique. L'objectif est de comprendre le fonctionnement de ce phénomène dans les deux langues de travail, anglais et espagnol, ce qui permettra établir ressemblances et différences entre elles. L'étude s'effectuera au moyen de l'analyse d'un corpus comparable de contrats de vente dans les deux langues. Afin de détecter les cas de variation synonymique dans les textes, nous utiliserons des marques textuelles pour établir une liste de patrons d'usage mesurant fréquence, productivité, fonctionnement et relation d'équivalence créé entre synonymes. Les résultats contribueront à comprendre comment la variation synonymique pourrait affecter la compréhension et interprétation des textes juridiques, spécifiquement en ce qui concerne la traduction, dans laquelle une gestion appropriée de cette stratégie peut être indispensable pour importer adéquatement le sens du texte source vers le texte cible.

\begin{abstract}
Synonymic variation is a common resource in specialized languages, particularly in legal language (Acuyo Verdejo 2004; Thiry 2009a; Barceló Martínez 2010). Since it is a semantic strategy, an erroneous interpretation can change the meaning of the text and the legal relationships created therein. Therefore, it is essential to detect it and manage it adequately. This paper takes a closer look at the use of synonymic variation within the legal field to understand how it works in English and Spanish for the purpose of setting up similarities and differences between them. Our research will be carried out through the analysis of comparable corpora of sales agreements in both languages. A series of textual markers will be used to detect the cases of synonymic variation in the texts in order to set a list of patterns of use regarding frequency, productivity, functioning and equivalence relationships created between synonyms. The results will help us understand how synonymic variation could affect the understanding and interpretation of legal texts, specifically regarding translation, where the management of this strategy can be essential to accurately transfer the meanings between source and target text.
\end{abstract}

\section{RESUMEN}

La variación sinonímica es un recurso habitual en los lenguajes de especialidad, especialmente en el lenguaje jurídico (Acuyo Verdejo 2004; Thiry 2009a; Barceló Martínez 2010). Dado que se trata de una estrategia semántica, una mala interpretación puede cambiar el significado del texto y las relaciones jurídicas establecidas en él; por ello, su correcta detección y manejo son fundamentales. El presente estudio pretende profundizar en la utilización de la variación sinonímica en el ámbito jurídico con el objetivo de 
comprender su funcionamiento en las dos lenguas de trabajo, inglés y español, y así poder establecer semejanzas y diferencias entre ellas. El estudio se llevará a cabo mediante el análisis de un corpus comparable de contratos de compraventa en ambas lenguas. Para detectar los casos de variación sinonímica en los textos utilizaremos una serie de marcadores textuales que nos permitirán establecer un listado de patrones de uso en cuanto a frecuencia, productividad, funcionamiento y relación de equivalencia creada entre los sinónimos. Los resultados nos ayudarán a entender en qué medida podría afectar la variación sinonímica a la comprensión e interpretación de los textos jurídicos y más específicamente en lo que respecta a la traducción, donde el manejo de esta estrategia puede ser clave en el correcto trasvase de significados entre el texto origen y el texto meta.

\section{MOTS-CLÉS/KEYWORDS/PALABRAS CLAVE}

synonymie, langage juridique, corpus comparable, contrat de vente, traduction juridique synonymy, legal language, comparable corpus, sales agreement, legal translation sinonimia, lenguaje jurídico, corpus comparable, contrato de compraventa, traducción jurídica

\section{Introducción}

La variación sinonímica es un tipo de relación semántica que se produce entre dos elementos del discurso que comparten su significado pero no su forma. Se trata de un recurso utilizado para guiar al receptor por el texto, permitiéndole decodificar los distintos significados de éste. Es un fenómeno que se ha mostrado controvertido a lo largo de la historia de la terminología, pues desde los inicios de la disciplina ha habido un pulso por defender una univocidad de los términos que ha acabado reconociéndose en muchos casos como inexistente. Concretamente en el ámbito jurídico, distintos estudios (Acuyo Verdejo 2004; Thiry 2009a; Barceló Martínez 2010; Pontrandolfo 2013) han señalado en los últimos tiempos no sólo la existencia, sino la abundancia, de la variación sinonímica en los textos jurídicos. En este sentido, Barceló Martínez destaca la importancia de ésta de cara especialmente a su traducción, hasta tal punto que "[...] cuanto mayor sea el manejo de estos usos, más éxito tendrá el proceso traslativo” (Barceló Martínez 2010: 32). Sin embargo, aún son escasos los estudios específicos que analizan en detalle cómo funciona este fenómeno en el discurso jurídico y cómo afecta a su comprensión, interpretación y traducción.

El presente trabajo pretende arrojar luz sobre el funcionamiento de la variación sinonímica con vistas a su aplicación en la práctica de la traducción y en su docencia. Se centrará en un aspecto concreto: la utilización de la referencia anafórica y catafórica para la creación de variación sinonímica en los textos jurídicos. El objetivo del presente trabajo es analizar cómo funcionan estos elementos dentro del discurso jurídico y contrastarlo en dos lenguas, inglés y español en sus variantes estadounidense y europea respectivamente, para observar similitudes y diferencias y poder determinar los efectos y consecuencias de su uso de cara a la traducción del texto. Todo ello se hará mediante un análisis contrastivo de corte funcional de un género textual específico, el contrato de compraventa, que es uno de los más habituales en la práctica jurídica. 


\section{Variación sinonímica, lenguaje jurídico y género}

\subsection{Variación sinonímica y lenguaje jurídico}

Los contenidos específicos de un texto, que dependen de cada género (Arellano y Díaz 2008), se articulan mediante enlaces intratextuales que permiten al receptor construir significados y así cohesionar la información, para lo cual se emplean recursos discursivos como la variación sinonímica. Como expusimos anteriormente, la variación sinonímica es una estrategia por la cual "[...] un significado puede estar representado en el plano de la expresión por más de un significante" (GarcíaHernández 1997: 5). Su materialización en el discurso ocurre mediante una alusión a un significado concreto que se considera el significante principal, denominado referente, y otros significantes que, con anterioridad o posterioridad a la aparición de ese referente, reiteran ese mismo significado mediante otras formas léxicas, denominadas variantes sinonímicas. Así, este recurso provoca una relación de referencia al establecer una vinculación entre la información nueva y la conocida, convirtiéndose en un importante mecanismo de cohesión. Para decodificar esta estrategia, el receptor debe ser capaz de identificar el referente y vincular a él todas las variantes sinonímicas con que se le vuelve a mencionar (Halliday y Hassan 1976).

La variación sinonímica así entendida se basa en la premisa de que tanto el referente como las variantes representan exactamente al mismo significado, es decir, que todos ellos tienen características equivalentes. Sin embargo, la literatura de este campo (Casas Gómez 1995; Lyons 1995; Barceló Martínez 2010; Goźdź-Roszkowski 2013, entre otros) afirma que esta circunstancia es, en la realidad, muy poco común, pues a la larga uno de los significantes tiende a utilizarse con mayor frecuencia y los demás suelen desaparecer. Por ello, para entender este fenómeno, los estudios en esta línea han determinado la existencia de distintos grados de equivalencia dentro del mismo, que dependerán de las características semánticas que compartan los significantes. Murphy (2003: 149) divide estas características en dos: core meanings, o características semánticas fundamentales, y peripheral features, o características semánticas secundarias. Las primeras son la base para determinar que existe una relación de sinonimia entre dos variantes, mientras que las segundas determinarán el mayor o menor grado de equivalencia entre ellas. Así, la variación sinonímica se divide en dos tipos fundamentales en función de la equivalencia entre variantes: sinonimia total o parcial.

La sinonimia total es aquella en la que dos elementos comparten todas sus características semánticas fundamentales y secundarias, de modo que dos unidades léxicas en esta circunstancia tienen la propiedad "[...] de ser intercambiables en todos los contextos” (Hernando Cuadrado 2003: 76). Frente a ella se situaría la sinonimia parcial, definida por el mismo autor como "[...] la cualidad que presentan dos o más unidades léxicas de ser semánticamente próximas, pero no intercambiables en todos los contextos"; es decir, variantes que comparten sus características semánticas fundamentales y que muestran distintos alcances de equivalencia en sus características semánticas secundarias. Este hecho no implica que no sean variantes sinonímicas válidas, sino que su idoneidad estará vinculada al contexto en que se utilizan (Sager 1990; Murphy 2003; Goźdź-Roszkowski 2013), hasta el punto de que es dentro de un contexto específico donde el término adquiere su especificidad, más concretamente en el ámbito jurídico (Chromá 2011: 38). 
Observamos con la existencia de esta dualidad que el uso de la variación sinonímica permite, mediante palabras distintas, tanto transmitir la misma información de distinta forma como transmitir información ligeramente diferente (Murphy 2003: 166). Ello hace que, en muchas ocasiones, estas distintas relaciones de equivalencia se utilicen como elemento de variación semántica para evitar la redundancia en el discurso, especialmente en los textos especializados (Suárez 2004: 63). Pero ¿cómo encaja esta dualidad en el lenguaje jurídico, supuesto ejemplo de precisión y especificidad? Dado que se trata de un ámbito cuyos textos tienen un foco contextual fundamentalmente instructivo, a priori debería significar que están redactados de forma inequívoca (Ferrari 2002). ¿Cuál es, entonces, la razón de ser de esta estrategia en el lenguaje jurídico?

Si estudiamos la literatura relacionada con el tema hasta la fecha constatamos que esa perspectiva de partida asociada habitualmente a los lenguajes de especialidad parece ser errónea (Regueiro Rodríguez 2010), y más específicamente aplicada a los textos jurídicos. Muy al contrario, numerosos autores como Mayoral (2004), Barceló Martínez (2010) o Pontrandolfo (2013) descartan la univocidad, exactitud y claridad de los textos jurídicos, constatando en cambio la existencia de variación, la búsqueda de efectos estéticos en la redacción y la importancia de la función expresiva, entre otros elementos. Tiersma (1999), además, confirma que el uso de la variación sinonímica específicamente está muy generalizado a pesar de lo supuestamente prescrito para la redacción de textos jurídicos, si bien es cierto que la incidencia de ambos tipos de sinonimia en los textos de este lenguaje especializado es muy distinta. La sinonimia total es muy escasa, limitándose fundamentalmente a fenómenos como términos aislados, caso de los sinónimos totales pleito y litigio en el español jurídico (Hernando Cuadrado 2003: 76), o al uso de dobletes y tripletes léxicos, mediante los cuales un sólo significado está denominado por el uso de parejas o tríos de sinónimos, y que son especialmente abundantes en el inglés jurídico (Bhatia 1993; Tiersma 1999; Alcaraz y Hughes 2002; Alcaraz, Campos et al. 2002; Mayoral 2007; Andrades Moreno 2014, entre otros). Por el contrario, la sinonimia parcial se presenta como un fenómeno mucho más habitual y complejo. El hecho de que la idoneidad como sinónimos de las variantes sinonímicas parciales quede vinculada al contexto en que se utilizan tiene como resultado que entre los sinónimos parciales existan, a su vez, diferentes relaciones de equivalencia. Ejemplo de ello puede ser el caso de que referente y variante sinonímica tengan distinto grado de especificidad semántica, lo cual da lugar a casos de hiperonimia (generalización) o hiponimia (especificación), que podrían ser totalmente válidos como sinónimos dentro del contexto a pesar de dicha diferencia.

Sin embargo, no sólo su idoneidad en contexto determina el uso de una variante sinonímica en el lenguaje jurídico, sino que también dependerá de la intención comunicativa del emisor. A este respecto, Thiry (2009b) divide la sinonimia del lenguaje jurídico en tres tipos: sinónimos estilísticos, cuyo uso está motivado por la intención de variar la expresión; definitorios, utilizados con afán de precisar otro término; y de enfoque, con los que según la variante que elija el emisor se subrayan determinados aspectos del contenido (Freixa, Fernández-Silva et al. 2008). Por último, pero no menos importante, la idoneidad de las variantes sinonímicas deberá quedar validada por la aceptabilidad de dichas formas dentro de la comunidad discursiva en que se produzca el texto, aceptabilidad determinada fundamentalmente por su frecuencia de uso. 
Como se puede apreciar, nos encontramos ante un fenómeno de una alta complejidad dadas las múltiples variables involucradas en su funcionamiento, por lo que su estudio se prevé igual de complejo. Para poder observar cuáles son las formas existentes y determinar por qué existen y cuál es la tipicalidad entre ellas es necesario estudiar la lengua "en uso y no como un sistema resultante de la suma de estructuras o reglas” (Diez 2009: 18). Por ello, nuestro estudio se basará en el análisis contrastivo de corte semántico-funcional, que parte de las similitudes percibidas entre distintas lenguas para determinar de qué formas se pueden expresar los significados en ellas y establecer la preferencia de una forma frente a otra, si existe, en un contexto determinado (Bondarko 1991; Chesterman 1998; Rabadán 2002). Dicho análisis se llevará a cabo sobre dos corpus, uno en español europeo y otro en inglés estadounidense, que nos permitirán centrarnos en un contexto específico mediante el uso de un género textual concreto, el contrato de compraventa. Así podremos describir en términos funcionales los recursos expresivos encontrados en dichos corpus elaborados con textos reales que reflejan esa lengua en uso para después contrastarlos con el objetivo final de encontrar semejanzas y diferencias entre ambas lenguas (Izquierdo 2008).

\subsection{Variación sinonímica y género: el contrato de compraventa}

Según la clasificación de los géneros jurídicos de Borja (2000), un contrato es un texto de aplicación del derecho de carácter instructivo que suscriben distintas partes con la intención de crear un pacto legalmente vinculante entre ellas. Se trata de uno de los géneros jurídicos más importantes, ya que regulan prácticamente todos los aspectos de la vida y convivencia de las sociedades actuales. Por esta razón consideramos de gran utilidad basar en él nuestro estudio.

Existen numerosos tipos de contratos, diferenciados principalmente según la naturaleza de las relaciones jurídicas tratadas en ellos, como compraventa, arrendamiento, empleo, etc. En el presente trabajo hemos decidido basarnos en el contrato de compraventa, definido por el Código Civil español en su artículo 1445 como aquel por el que "uno de los contratantes se obliga a entregar una cosa determinada y el otro a pagar por ella un precio cierto, en dinero o signo que lo represente". Se trata de un género común a distintos ordenamientos jurídicos, lo cual hace de él un candidato idóneo para su contraste. Nos centraremos en los ordenamientos jurídicos estadounidense y español y sus lenguas, dado que existen grandes diferencias entre países incluso cuando comparten la misma lengua y tienen sistemas afines (Šarčević 1991: 616), por lo que un estudio más amplio sería inabarcable para este trabajo, que puede tomarse como punto de partida para una futura profundización.

Tal y como afirma Mayoral (2007: 55), "la validez de un contrato no depende de su redacción ni de su estructura sino de las obligaciones que establece”, aún más en el caso de los ordenamientos estadounidense y español, los cuales no especifican la estructura que éstos deben tener, sino sus contenidos. A pesar de ello se trata de un género textual con una estructura retórica muy estereotipada (Borja 2000: 84), lo que influye no sólo en la forma en que se organiza la información, sino también en el tipo de lenguaje que se utiliza.

En lo que respecta a la estructuración retórica, siguiendo el estudio de Mayoral (2007) observamos que en ambos ordenamientos jurídicos coinciden, de forma general, los siguientes elementos: 
- fecha en el comienzo

- presentación de las partes en el preámbulo

- exponendos

- cláusulas o estipulaciones

- fórmula de conclusión

No obstante, no se trata de una coincidencia total, dado que cada apartado tiene sus propias características en cada ordenamiento, como por ejemplo muestra el hecho de que a la fecha se le añada el lugar en los contratos españoles o de que el documento y las cláusulas en los contratos estadounidenses lleven un título.

En cuanto al lenguaje, siguiendo los estudios de Alcaraz y Hughes (2002) y Alcaraz, Campos et al. (2002), en ambas lenguas destacan los siguientes usos:

- complejidad terminológica propia del lenguaje jurídico (convivencia de términos propios del lenguaje jurídico con términos del lenguaje común que adquieren un significado específico dentro de este registro)

- uso de fórmulas estereotipadas

- redundancias (dobletes, tripletes)

- términos arcaizantes

- complejidad sintáctica (subordinaciones, oraciones muy extensas)

- elevado uso de la voz pasiva

- nominalizaciones

A pesar de tratarse de una clasificación no exhaustiva, observamos que, en general, también existen múltiples elementos lingüísticos coincidentes en ambas lenguas y ordenamientos, lo cual hará factible la observación de rasgos comunes de cara a un análisis contrastivo, y así mismo en lo que respecta al uso de la variación sinonímica.

\section{Metodología}

\subsection{Marcadores textuales}

Como argumentamos anteriormente en el apartado 2.1, los distintos grados de equivalencia, total o parcial, suponen una dificultad en lo que concierne a la variación sinonímica. Sin embargo, no es el único problema, pues también presenta una dificultad añadida la forma en que dichas relaciones se plasman en el texto. Dado que estamos ante una repetición de un elemento, para identificar e interpretar correctamente esta relación es necesario localizar el referente inicial sobre el que se vuelve a incidir. Desafortunadamente no es tarea fácil en muchas ocasiones, pues encontramos casos en que un referente y su variante se encuentran muy distanciados entre sí; ocasiones en que una variante podría hacer referencia a más de un referente si se trata de un sinónimo demasiado general, etc. Por ello, para poder obtener datos sobre la variación sinonímica e intentar comprender su comportamiento es necesario encontrar aquellos mecanismos que permitan detectar de forma fiable en qué casos se está estableciendo un vínculo con otro elemento presente en el texto. Estos mecanismos son lo que se denominan marcas textuales.

Existen diversos tipos de marcas textuales que indican que se está produciendo la repetición especificada anteriormente, entre los que cabe destacar (Halliday y Hassan 1976; González 2014): 
- Reformuladores: marcadores del discurso cuya función es reformular una información que se ha introducido previamente, como pueden ser that is to say en inglés o es decir en español

- Marcadores anafóricos/catafóricos: partículas que acompañan a las unidades lingüísticas para identificar que son una reiteración de otro elemento que ha aparecido o va a aparecer en el texto, como los determinantes demostrativos this en inglés o este, esta en español

- Signos de puntuación de naturaleza aclaratoria o utilizados para introducir información complementaria, como paréntesis, comillas o guiones

- Conjunciones como and/or en inglés o $y / o$ en español, que entre otras funciones actúan como marcas de la existencia de un encadenamiento de sinónimos en el caso de elementos como dobletes y tripletes

De entre estas marcas, aquellas que indican de forma más explícita la presencia de variación en el texto son los marcadores anafóricos y catafóricos, dado que las demás tienen esta labor entre sus funciones pero no se limitan a servir para ello. Además, como afirma González (2014: 23), los elementos anafóricos son "una de las principales características de los textos jurídico-administrativos desde el punto de vista lingüístico", por lo que parece natural que centremos en ellos nuestro estudio de la variación sinonímica.

Como señalan Halliday y Hasan (1976: 31), anáfora y catáfora son dos caras de un mismo fenómeno por el cual un elemento no puede ser interpretado semánticamente por sí mismo. En su lugar, dicha interpretación depende de la existencia de un elemento semánticamente equivalente en el contenido lingüístico anterior, en el caso de la anáfora, o posterior, en el caso de la catáfora (Botley y McEnery 2000: 5). Tal y como se argumentó anteriormente, localizaremos ese elemento semánticamente equivalente mediante una serie de marcadores que guían hacia la localización del referente.

Como base para elaborar nuestro listado para el presente trabajo hemos partido de los recopilados por González (2014) en su trabajo sobre los marcadores anafóricos en el lenguaje jurídico. A ellos hemos añadido algunos similares, también abundantes según nuestra experiencia, lo que resulta en la siguiente relación, que será la utilizada en nuestro análisis:

- Determinantes demostrativos: this, that, these, those y such (5) en inglés y sus correspondientes en español este, ese, aquel, tal y sus variantes de género y número (14). Para este estudio no tendremos en consideración su función pronominal, pues en ella se produce una sustitución del referente y nuestro interés es observar las variantes sinonímicas con que se sustituye, por lo que nos centraremos en su función adjetival

- Adjetivos deverbales de participio: En el inglés jurídico encontramos said, mentioned, el prefijo afore (y sus variantes: aforesaid, aforementioned...), referred to as, known as y named (6). Los correspondientes en español serían aducido, aludido, citado, dicho, expresado, expuesto, indicado, referido, mencionado, mentado, meritado, nombrado, referenciado, reseñado, señalado, transcrito y sus variantes de género y número (64)

- La construcción artículo + mismo

- La construcción artículo + presente 


\subsection{Compilación del corpus y fases del análisis}

Una vez seleccionado el género específico, el de los textos de aplicación del derecho, ámbito en el que puede tener más consecuencias el uso de las distintas relaciones de equivalencia entre referentes y variantes, y más concretamente los contratos de compraventa, se compiló un corpus comparable. Se trata de una tipología de corpus formada por textos en distintas lenguas origen y que "presentan una serie de semejanzas” (Rabadán y Fernández 2002: 53) en cuanto a principios de selección y función comunicativa. En este caso concreto se trata de contratos de compraventa en español europeo e inglés estadounidense escritos por especialistas y que cuenta tanto con documentos originales como formularios. El uso de este corpus nos ayudará a comprender cómo funcionan las relaciones anafóricas y catafóricas de variación sinonímica dentro de los textos jurídicos.

El tamaño del corpus se determinó siguiendo las recomendaciones de autores como Biber (1990), quien considera que el número adecuado de palabras en un corpus para un estudio de la variación está entre 40.000 y 400.000, acotable a 200.000 cuando se trata de textos de ámbito muy restringido (Goźdź-Roszkowski 2011: 28), como es nuestro caso. Así, nuestro corpus consta de un total de 470.485 palabras, y se trata de un corpus comparable formado, a su vez, por dos subcorpus, uno de textos redactados en inglés estadounidense, con 204.685 palabras, y uno de textos redactados en español europeo, con 265.800 palabras.

Una vez compilado el corpus dividimos su análisis en diferentes fases. En primer lugar, para poder obtener datos concretos en textos de carácter tan multidisciplinar como los contratos de compraventa, en los cuales se hace referencia a temáticas dispares como legislativa, bancaria o arquitectónica, recopilamos los términos clave del género textual para poder restringir nuestra búsqueda a las variantes sinonímicas que aparecían sobre dichos términos. La recopilación de los términos clave se realizó sobre nuestro propio corpus, obteniendo un listado de las palabras más frecuentes mediante la herramienta del gestor de corpus AntConc (Anthony 2014) ${ }^{1}$. Para ello introdujimos una lista de excepciones formada por palabras generales como conjunciones, preposiciones, etc., así como palabras propias del formato estereotipado del género (enumeraciones, etc.) que quedaban fuera del alcance de nuestro estudio. El listado final se obtuvo en función del número de ocurrencias detectadas en el corpus: se estableció que un término clave debía presentar un mínimo de 20 apariciones en al menos 5 textos diferentes para asegurar su representatividad en el campo.

A continuación, utilizando el mismo gestor, analizamos cada subcorpus mediante el uso de nuestros marcadores anafóricos/catafóricos para localizar aquellos casos en que éstos marcaban la existencia de variación sinonímica entre dos elementos del texto de entre los términos clave extraídos. Para ello, así como para localizar cuáles de nuestros marcadores se empleaban en el corpus, introdujimos cada marcador en la opción de búsqueda y analizamos aquellos que aparecían caso a caso en su oración en contexto. Nos centramos específicamente en cuatro aspectos:

- productividad de los marcadores anafóricos/catafóricos, para determinar hasta qué punto son útiles en la detección de relaciones de variación sinonímica y averiguar si funcionan de forma parecida en ambas lenguas

- posición de la variante con respecto al referente para determinar si es más habitual la anáfora o la catáfora y si es igual en ambas lenguas 
- patrones de variación sinonímica, para comprender cómo se crean las relaciones entre referente y variante en ambas lenguas

- grado de equivalencia entre referente y variante, lo que nos permitirá determinar si es más habitual la sinonimia total o alguna de las variedades de la parcial y en qué medida

Con los datos obtenidos pudimos realizar un análisis contrastivo entre las dos lenguas de trabajo para realizar generalizaciones sobre el funcionamiento del fenómeno, del cual damos cuenta en el siguiente apartado.

\section{Resultados}

\subsection{Productividad de los marcadores anafóricos/catafóricos}

\section{GRÁfICA 1}

Productividad de los marcadores

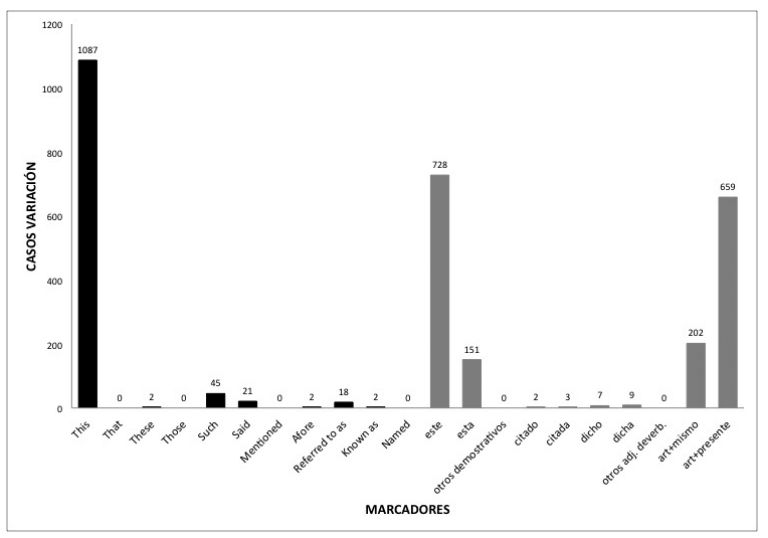

Los resultados del análisis llevado a cabo sobre nuestro corpus, del que se han extraído todos los ejemplos que se expondrán a continuación, muestran que los marcadores anafóricos y catafóricos son herramientas productivas y habituales en la creación de variación sinonímica en el lenguaje jurídico en ambas lenguas. En nuestro corpus, los casos de variación sinonímica creados por esos marcadores fueron 1177 en inglés y 1761 en español. La diferencia observada entre estas cifras es reflejo del superior número de palabras del subcorpus español con respecto al inglés, por lo que no resulta significativa.

Considerando cada marcador de forma individual, los determinantes demostrativos son los más productivos en ambas lenguas, específicamente las formas del singular. En inglés, this muestra una incidencia de 1087 casos, mientras que este, esta en español muestra una incidencia de 879 casos. Además, se ha encontrado una pequeña incidencia de la forma plural these en inglés, con solamente dos casos, pero ningún resultado para las formas plurales en español.

1) The Seller now owns the following described real estate [...]. The Seller agrees to sell and the Buyer agrees to buy this property for the following price.

[El Vendedor es el actual propietario del inmueble descrito a continuación [...]. El Vendedor acuerda vender y el Comprador acuerda comprar esta propiedad por el siguiente precio] 
2) La vivienda descrita está gravada con una hipoteca a favor del Banco $[\ldots]$, respondiendo esta finca de Euros de principal para intereses.

(Subrayado propio)

Sin embargo, los determinantes demostrativos no son los más productivos si analizamos los marcadores en conjunto dentro de sus categorías. En ambas lenguas la categoría más productiva fue la de los adjetivos deverbales de participio: en inglés resultaron productivos en la creación de variación sinonímica el $71 \%$ de los marcadores de esta categoría frente a una productividad del 50\% del conjunto de determinantes demostrativos. Los resultados en español fueron similares, pues los adjetivos deverbales de participio mostraron una productividad del $21 \%$ frente al $14 \%$ de los determinantes demostrativos en conjunto. Es importante tener en cuenta que los porcentajes en español son considerablemente inferiores con respecto al inglés debido a que se contabilizaron prácticamente el doble de marcadores al haberse tenido en cuenta las formas de masculino y femenino.

\subsection{Posición}

La anáfora es significativamente más habitual que la catáfora en ambas lenguas. Sin embargo, es sustancialmente más común en español: de los 1761 casos de variación sinonímica en español se encontraron 79 casos de catáfora, frente a los solo tres casos de catáfora encontrados entre los 1177 casos de variación en inglés. Cabe destacar, además, que todos los casos de catáfora en español se asocian al uso de un mismo marcador, artículo + presente. Sin embargo, dado que en español su incidencia también es muy escasa, no consideramos que este hecho sea excesivamente significativo en términos contrastivos.

\subsection{Patrones de variación sinonímica}

El análisis ha revelado cuatro patrones de variación sinonímica habituales en ambas lenguas, además de un patrón adicional que se ha detectado exclusivamente en español.

TABLA 1

Patrones de variación sinonímica por frecuencia

\begin{tabular}{|l|c|l|c|}
\hline \multicolumn{1}{|c|}{ INGLÉS } & Casos & \multicolumn{1}{|c|}{ ESPAÑOL } & Casos \\
\hline $\begin{array}{l}\text { 1. Sustitución hiperónimo-hipónimo } \\
\text { (parte del referente) }\end{array}$ & 740 & $\begin{array}{l}\text { 1. Sustitución hiperónimo-hipónimo } \\
\text { (parte del referente) }\end{array}$ & 872 \\
\hline $\begin{array}{l}\text { 2. Sustitución léxica mediante } \\
\text { sinónimo total }\end{array}$ & 288 & $\begin{array}{l}\text { 2. Sustitución mediante proforma } \\
\text { léxica }\end{array}$ & 562 \\
\hline $\begin{array}{l}\text { 3. Sustitución mediante proforma } \\
\text { léxica }\end{array}$ & 145 & 3. Sustitución por marcador & 202 \\
\hline $\begin{array}{l}\text { 4. Sustitución hiperónimo-hipónimo } \\
\text { (sinónimo parcial del referente) }\end{array}$ & 4 & $\begin{array}{l}\text { 4. Sustitución léxica mediante } \\
\text { sinónimo total }\end{array}$ & 92 \\
\hline & $\begin{array}{l}\text { 5. Sustitución hiperónimo-hipónimo } \\
\text { (sinónimo parcial del referente) }\end{array}$ & 33 \\
\hline
\end{tabular}




\subsubsection{Sustitución hiperónimo-hipónimo (parte del referente)}

3) The court shall determine the prevailing party. The term "expenses" as used herein means any expenses incurred in connection with any of the out of court or state, federal or bankruptcy proceedings referenced above, including but not limited to the fees and expenses of any appraisers, consultants and expert witnesses retained or consulted by such party.

[El tribunal determinará cuál es la parte vencedora. El término "costas" se entenderá como cualquier desembolso realizado en relación con cualquiera de los procedimientos extrajudiciales, estatales, federales o por quiebra anteriormente mencionados, incluidos de forma no exclusiva los honorarios y gastos de cualquier tasador, consultor o testigo experto contratado o consultado por dicha parte]

(Traducción y subrayado propios)

4) SEGUNDO. - Que la vivienda con sus elementos comunes y anexos descritos están en construcción en fase de ................. habiendo sido otorgada escritura pública de declaración de obra nueva y de división de la propiedad horizontal ante el Notario de ............., D./Da. el día no. de protocolo debidamente inscrita en el Registro de la Propiedad con los datos que constan en el apartado precedente, figurando en $\underline{l a}$ citada escritura los Estatutos de la Comunidad.

(Subrayado propio)

En este patrón la variación sinonímica consiste en el uso de una parte del referente como sinónimo del referente completo, tal y como muestran los siguientes ejemplos:

\section{TABLA 2}

Ejemplos de sustitución hiperónimo-hipónimo (parte del referente)

\begin{tabular}{|l|l|l|l|}
\hline \multicolumn{1}{|c|}{ Referente (IN) } & \multicolumn{1}{|c|}{ Variante (IN) } & \multicolumn{1}{|c|}{ Referente (ES) } & Variante (ES) \\
\hline $\begin{array}{l}\text { agreement for } \\
\text { purchase and sale }\end{array}$ & agreement & contrato privado de compraventa & contrato \\
\hline closing date & date & compraventa de vivienda & compraventa \\
\hline real property & property & $\begin{array}{l}\text { impuesto sobre transmisiones } \\
\text { patrimoniales y actos jurídicos } \\
\text { documentados }\end{array}$ & impuesto \\
\hline $\begin{array}{l}\text { earnest money } \\
\text { deposit }\end{array}$ & earnest money & parte vendedora & parte \\
\hline
\end{tabular}

Según los datos obtenidos, en este patrón se recurre fundamentalmente al uso del elemento léxico más general del referente para sustituirlo, tanto en inglés como en español. Esto implica que la variante sinonímica es menos específica en cuanto a su significado y, por tanto, es un hiperónimo del referente. Sin embargo, ambas formas actúan como sinónimos totales en contexto.

Este patrón es el más frecuente en ambas lenguas, con 740 casos en inglés y 872 en español.

\subsubsection{Sustitución léxica mediante sinónimo total}

5) [...] the sole obligation of Seller shall be to reimburse Purchaser for the actual costs incurred for Purchaser's title. Upon making such refund, this Contract shall be cancelled and neither Party shall have any further claim against the other hereunder. 
[...] la única obligación del Vendedor será reembolsar al Comprador los costes en que se haya incurrido por el título de propiedad del Comprador. Una vez realizado dicho reintegro, el presente Contrato quedará rescindido y ninguna de las Partes podrá realizar ninguna reclamación a la otra a partir de ese momento]

(Traducción y subrayado propios)

6) Ambos intervienen en su propio nombre y derecho, reconociéndose la capacidad legal necesaria para realizar esta compraventa y, EXPONEN [...] Segunda. - El precio de esta venta es de [] euros.

(Subrayado propio)

Este patrón implica la sustitución del referente por un sinónimo total. En este caso, ambas formas se encuentran semánticamente al mismo nivel.

TABLA 3

Ejemplos de sustitución léxica mediante sinónimo total

\begin{tabular}{|l|l|l|l|}
\hline \multicolumn{1}{|c|}{ Referente (IN) } & \multicolumn{1}{|c|}{ Variante (IN) } & \multicolumn{1}{c|}{ Referente (ES) } & \multicolumn{1}{c|}{ Variante (ES) } \\
\hline refund & reimburse & $\begin{array}{l}\text { compraventa de } \\
\text { inmueble }\end{array}$ & transmisión patrimonial \\
\hline provision & terms & \\
\hline
\end{tabular}

La sustitución léxica mediante un sinónimo total del referente es el segundo patrón más común en inglés con 288 casos. Sin embargo, en español es el cuarto patrón en términos de frecuencia con 92 casos.

\subsubsection{Sustitución mediante proforma léxica}

7) Receipt of \$

Check Cash as Earnest Money Deposit, to be deposited in accordance with the terms and conditions of the Terms Paragraph 4.B. Broker(s) acknowledges receipt of Earnest Money and Listing Broker, if applicable, shall deposit said funds in accordance with Paragraph 4 of this Contract.

[Recibo de un Cheque en Metálico por \$ como Fianza, que será depositado de conformidad con las Estipulaciones especificadas en el Apartado 4.B. El(los) agente(s) acusan el recibo de la fianza y el agente inmobiliario, si corresponde, depositará dichos fondos de conformidad con el Apartado 4 del presente Contrato]

(Traducción y subrayado propios)

8) [...] casados en régimen de gananciales; quienes a partir de este momento y en el presente documento serán designadas como parte COMPRADORA MANIFIESTAN: $1^{\circ}$.- Que es intención de las partes intervinientes celebrar un contrato de COMPRAVENTA DE VIVIENDA, el cual se regirá por las cláusulas que más adelante se detallarán.

(Subrayado propio)

Las proformas léxicas son elementos léxicos semánticamente muy amplios que se emplean para generalizar o resumir un elemento que ha aparecido previamente (Marimón 2008: 134). Por tanto, en este patrón se generaliza al referente mediante el uso de una variante sinonímica menos específica que actúa como sinónimo total en contexto. 
TABLA 4

Ejemplos de sustitución mediante proforma léxica

\begin{tabular}{|l|l|l|l|}
\hline \multicolumn{1}{|c|}{ Referente (IN) } & Variante (IN) & \multicolumn{1}{|c|}{ Referente (ES) } & Variante (ES) \\
\hline contract of sale & document & $\begin{array}{l}\text { compraventa de bienes } \\
\text { inmuebles }\end{array}$ & acto \\
\hline liens or encumbrances & matters & principal & cantidad \\
\hline downpayment & amount & $\begin{array}{l}\text { contrato de compraventa de } \\
\text { bien inmueble }\end{array}$ & documento \\
\hline
\end{tabular}

A pesar de que algunos investigadores consideran que las proformas léxicas son una forma de hiperonimia, en este trabajo las hemos considerado como una categoría propia. Esta decisión viene motivada por el distinto alcance semántico de las proformas léxicas con respecto a los otros hiperónimos encontrados en nuestro corpus: el significado de las primeras es demasiado difuso o impreciso, de modo que podría aplicarse a múltiples referentes, mientras que el significado de los segundos es comparativamente más específico.

Este patrón es más común en español, dado que se trata del segundo más frecuente con 562 casos. Por su parte, la sustitución mediante proforma léxica en inglés ocupa el tercer puesto en cuanto a frecuencia con 145 casos.

\subsubsection{Sustitución hiperónimo-hipónimo (sinónimo parcial del referente)}

9) The Seller now owns the following described real estate, located at City of , State of : For valuable consideration, the Seller agrees to sell and the Buyer agrees to buy this property for the following price and on the following terms.

[El Vendedor es el actual propietario del inmueble descrito a continuación, sito en , ciudad de , Estado de : Como contraprestación onerosa, el Vendedor acuerda vender y el Comprador acuerda comprar esta propiedad por el siguiente precio y de conformidad con las siguientes estipulaciones]

(Traducción y subrayado propios)

10) La vivienda descrita está gravada con una hipoteca a favor del Banco constituida por escritura autorizada por el Notario D. respondiendo esta finca de

Pesetas de principal.

(Subrayado propio)

En este patrón el referente es sustituido por un sinónimo parcial que, sin embargo, actúa como total en contexto.

TABLA 5

Ejemplos de sustitución hiperónimo-hipónimo (sinónimo parcial del referente)

\begin{tabular}{|l|l|l|l|}
\hline \multicolumn{1}{|c|}{ Referente (IN) } & Variante (IN) & Referente (ES) & Variante (ES) \\
\hline agreement to purchase & contract & inmueble & vivienda \\
\hline real property & premises & comprador & parte \\
\hline real property & lot & documento & contrato \\
\hline
\end{tabular}


Como muestran los ejemplos de la Tabla 5, este patrón puede seguir distintas estrategias. En primer lugar, observamos variación mediante el uso de un sinónimo de una parte específica del referente, es decir, un hiperónimo. Prueba de ello es el primer ejemplo en inglés (agreement $>$ contract). En segundo lugar, encontramos variación sinonímica mediante el uso de un término más específico como muestran los ejemplos primero y tercero en español. Por tanto, la variante utilizada es un hipónimo del referente. Por último, encontramos variación sinonímica mediante el uso de un término menos inclusivo, como es el caso de los ejemplos dos y tres en inglés y el segundo ejemplo en español. Mediante esta última estrategia, la variante utilizada es de nuevo un hiperónimo del referente.

Por su parte, este patrón es el menos común en ambas lenguas, con una incidencia de 33 casos en español y solo cuatro en inglés.

\subsubsection{Sustitución por marcador}

11) El vendedor ha obtenido de la Caja ....... un préstamo con la garantía hipotecaria de las viviendas antes mencionadas, para la construcción y, posterior adquisición de las mismas, en virtud de escritura pública de fecha...

(Subrayado propio)

Este patrón sólo se ha encontrado en el corpus en español. Consiste en la sustitución del referente por el marcador anafórico/catafórico en cuestión; dicho patrón no parece ser válido con todos los marcadores, dado que sólo hemos encontrado sustituciones mediante el marcador artículo + mismo en sus distintas variantes:

TABLA 6

Ejemplos de sustitución por marcador

\begin{tabular}{|l|l|}
\hline \multicolumn{1}{|c|}{ Referente (ES) } & \multicolumn{1}{c|}{ Variante (ES) } \\
\hline parte compradora & la misma \\
\hline viviendas & las mismas \\
\hline inmueble & el mismo \\
\hline
\end{tabular}

A pesar de ser un recurso empleado exclusivamente en español, es el tercer patrón más frecuente en esta lengua con 202 casos.

\subsection{Nivel de equivalencia}

En general la mayoría de referentes y variantes no son equivalentes totales, dado que no podrían intercambiarse en cualquier situación, tanto si se produce generalización como especificación del referente. Sin embargo, hemos observado que funcionan como sinónimos dentro del texto una vez el referente ha sido especificado.

\subsection{Conclusión del análisis contrastivo}

Como hemos observado en este apartado, podemos afirmar que la variación sinonímica creada mediante marcadores anafóricos y catafóricos es un elemento clave en el lenguaje jurídico según los datos recogidos en el análisis de nuestro corpus por tres razones fundamentales: en primer lugar, se trata de un fenómeno que afecta a 
aspectos básicos de la comprensión del texto y dadas las relaciones semánticas que crea es un elemento indispensable en su composición. Además, según los datos obtenidos, resulta ser lo suficientemente frecuente como para considerarlo significativo. Por último, presenta unos patrones de uso concretos y que se repiten en nuestro análisis, existiendo además muchas similitudes en su funcionamiento y frecuencia en ambas lenguas de estudio; éstas resultan muy interesantes de cara al análisis de sus implicaciones para la traducción, en el cual incidimos en el siguiente apartado.

\section{Implicaciones para la traducción}

De forma general, los problemas semánticos en la traducción jurídica suelen asociarse a tres motivos principales: el primero, la falta de equivalencia de figuras entre los distintos ordenamientos (Borja 2000: 9); el segundo, la falta de conocimiento experto del traductor sobre algún concepto; por último, la imposibilidad por parte del traductor de interpretar los significados de los elementos léxicos o sintácticos del texto. Los dos primeros problemas están relacionados con la competencia del traductor como especialista, que va construyendo su conocimiento experto gracias a una profunda labor de documentación (Román Mínguez 2012); así será capaz de identificar, interpretar y plasmar en la lengua meta los aspectos relevantes del texto origen de modo que el receptor construya la estructura cognitiva deseada en el contexto meta (Engberg 2017). El tercer problema, por su parte, está fundamentalmente relacionado con la falta de concreción de las unidades léxicas en el texto jurídico. Esta imprecisión está producida por fenómenos como la sinonimia o la difícil detección de referentes anafóricos (Moreno Pérez 2017), así como por la imprecisión típica del lenguaje jurídico (Orts Llopis 2005). Para abordarlo, el traductor deberá estar familiarizado con el funcionamiento de estos fenómenos, lo que le permitirá detectarlos, analizarlos y trasvasarlos de modo que se mantengan las implicaciones jurídicas del texto origen (TO) en el texto meta (TM). La incidencia de la variación sinonímica en los textos jurídicos observada en el presente estudio parece confirmar que este tercer problema es habitual, por lo que intentaremos enumerar unas pautas de actuación que ayuden al traductor a enfrentarse a él con éxito.

Basándonos en los hallazgos del presente estudio, el primer paso que un traductor debería seguir para afrontar la variación sinonímica creada mediante marcadores anafóricos y catafóricos es permanecer alerta ante la aparición de los propios marcadores en el texto. Dada su productividad a la hora de crear variación sinonímica, una vez detectados sería necesario determinar si, efectivamente, los marcadores están señalando una variante. En ese caso, el traductor tendría que dar el segundo paso, que sería localizar el referente. Como mencionamos anteriormente, la dificultad radica en que, en múltiples ocasiones, se encuentran muy lejos el uno del otro, por lo que hay que realizar una lectura muy minuciosa para detectarlo. Todo ello teniendo en cuenta el habitual obscurantismo propio del lenguaje jurídico que, en ocasiones, hace que los referentes parezcan estar encriptados.

Detectados referente y variante, el traductor podrá observar qué patrón de variación sinonímica se ha empleado en el TO, lo cual le permitirá determinar la relación existente entre ellos (hiperónimo-hipónimo, sinónimos totales, etc.). Esto será esencial para proceder al tercer paso, que sería la elección de la estrategia para trasvasarlo 
al TM. Aquí al traductor podría planteársele una disyuntiva: elegir mantener el mismo patrón del TO o emplear un patrón diferente que se emplee también en ambas lenguas.

Mantener el mismo patrón supondría, por ejemplo, buscar ante un patrón hiperónimo-hipónimo dos términos que mantengan la misma relación en la lengua meta. Esta elección comporta una serie de ventajas: en primer lugar, el traductor mantendría la intencionalidad del redactor del TO cuando eligió esa estrategia específica y no otra (por ejemplo, que el redactor del TO eligiera un hipónimo como variante puede implicar que se quiso especificar el referente). Además, mantendría el alcance de los conceptos implicados (por ejemplo, mediante la vaguedad en el TO se pudo pretender que todos los supuestos jurídicos posibles quedaran contemplados). Por último, se trata de una estrategia más rápida para el traductor al no tener que construir una reformulación, lo cual no es baladí dada la premura que se exige habitualmente a estos profesionales.

Por otro lado, emplear un patrón diferente al del TO permite al traductor ejercer una traducción menos encorsetada y literal, algo que muchos autores consideran deseable en traducción jurídica (Engberg 2002; Ferrán 2004; Bestué y Orozco 2011). Esta estrategia podría, además, ser necesaria si el traductor considera que la relación referente-variante no es suficientemente clara o puede inducir a error (por ejemplo, el cambio de orden de los complementos en una reformulación sintáctica podría conllevar que el referente pueda ser dos elementos distintos). El traductor podría elegir tanto sustituir la variante por una reiteración del referente como utilizar otro patrón de variación (por ejemplo, cambiar una variante que es sinónimo parcial por otra que sea un sinónimo total).

Todas estas estrategias pueden ser válidas, y este artículo no pretende ser prescriptivo en este sentido, sino simplemente analizar las posibilidades desde el punto de vista del traductor para intentar prepararlo para la toma de decisiones. Con este fin, nos parece necesario señalar los posibles inconvenientes de una aproximación poco concienzuda al fenómeno de la variación sinonímica, independientemente de la estrategia que se emplee.

La premura que se exige habitualmente al profesional impide, en más ocasiones de las que se desearía, hacer un estudio lo suficientemente profundo de términos que, de forma superficial, pueden parecer iguales. En caso de no prestarle suficiente atención a la variación sinonímica y no detectarse, podría recurrirse inintencionadamente a una traducción automatizada palabra por palabra sin llevar a cabo esta fase de análisis y/o documentación. Como consecuencia, podría producirse una pérdida del sentido del texto (por ejemplo, el lector del TM podría no encontrar el referente o incluso confundirlo con otro si no se hacen concordar la variante o el marcador con el referente en caso de que tengan flexión de género).

Cabe también la posibilidad de que, sin esa fase de análisis y/o documentación que surge al localizar el fenómeno, el traductor varíe, sin ser consciente, la intencionalidad con que el autor del TO eligió una estrategia específica o el alcance de la relación referente-variante (por ejemplo, si elige un término más inclusivo que el del TO). Esto podría acarrear un cambio en las implicaciones jurídicas del texto, lo cual supondría un error grave. Todo lo anterior teniendo en cuenta que, además del aspecto semántico, también será necesario prestar atención a la aceptabilidad: los términos elegidos deberán resultar familiares para el experto y ser propios del 
género textual con que se esté trabajando o, de otro modo, la traducción podría no ser aceptada por la comunidad a la que pertenece dicho género.

Observamos que las posibles implicaciones de este fenómeno en la traducción son diversas a la par que importantes, pues de su correcto manejo depende en gran medida la consecución de una traducción adecuada. Vemos a su vez que el aspecto semántico no sólo se limita a los conceptos que subyacen a los términos especializados, sino que el significado de éstos se puede retorcer de maneras muy diferentes que el traductor debe estar preparado para descifrar e interpretar. Por ello es necesario conocer cómo funcionan en los textos estas relaciones de variación sinonímica y qué alcance pueden tener para que el traductor esté preparado para solventarlas siendo consciente de sus matices e implicaciones.

\section{Conclusión}

En el presente trabajo, tras el análisis del corpus comparable, hemos detectado que la variación sinonímica es un fenómeno común en este tipo de textos y que, además, comparte similitudes entre ambas lenguas de estudio en términos de estrategias empleadas, mostrando ambas patrones de variación similares.

Así mismo, hemos confirmado la complejidad del fenómeno, pues el concepto ortodoxo de equivalencia total y parcial se desdibuja en el caso de la variación sinonímica encontrada en nuestro estudio, al emplearse como equivalentes totales variantes que no lo son. Lejos de la univocidad soñada, la productividad que muestra esta estrategia entre los expertos viene a confirmar que en los textos jurídicos hay lugar para la creatividad y la función expresiva.

Por último, hemos constatado que la variación sinonímica es de vital importancia en los textos jurídicos: la principal consecuencia de su uso es que se crea para el receptor una obligación de interpretar una red de significantes asociados al mismo significado, así como su alcance, que en la mayoría de ocasiones puede parecer contradictorio a simple vista. Sin la interpretación de dicha red no es posible decodificar el significado del texto, lo que demuestra el enorme impacto del fenómeno en el acto comunicativo en que éstos se encuadran.

Todo lo anterior, evidentemente, tiene consecuencias directas sobre la aplicación de nuestro estudio: la traducción. La importancia de una correcta interpretación de la variación sinonímica en el texto origen es esencial, constatándose la necesidad de llevar a cabo una minuciosa labor de detección del fenómeno y de identificación del referente adecuado en cada caso. Sólo así el traductor podrá ser lo suficientemente preciso en el alcance que otorgue a referentes y variantes, todo ello teniendo en cuenta la intencionalidad, no menos importante, con que las eligió el emisor.

Así, el fenómeno de la variación sinonímica obliga especialmente al traductor a tener muy en cuenta las implicaciones que una traducción imprecisa de estas relaciones puede conllevar, pues según el alcance de un error en el trasvase de la variación sinonímica en estos textos, el resultado podría derivar en consecuencias jurídicas para las partes implicadas o incluso para el propio traductor.

Por todo esto, consideramos que el presente trabajo proporciona datos que señalan la importancia del fenómeno de la variación sinonímica en el texto jurídico y, más específicamente, la generada por la anáfora y la catáfora. En futuras investigaciones nos gustaría seguir ampliando la investigación aquí comenzada aplicando la 
metodología a otros géneros con el objetivo de poder determinar si este fenómeno se produce en el lenguaje jurídico en general y si funciona de la misma forma en otros géneros jurídicos. Asimismo, podría servir de base para establecer unas herramientas traductológicas que permitan sistematizar y ayudar al traductor en su labor.

\section{NOTAS}

1. Anthony, Laurence (2014): AntConc. Versión 3.2. Tokio: Waseda University.

\section{REFERENCIAS}

Acuyo Verdejo, María Carmen (2004): La sinonimia, la polisemia y la hiperonimia en el lenguaje jurídico de la Unión Europea: el caso de las citaciones judiciales. In: Rita Temmerman y Uus Knops, eds. The Translation of Domain Specific Languages and Multilingual Terminology Management. Linguistica Antverpiensia. 3:67-81.

Alcaraz, Enrique y Hughes, Brian (2002): El español jurídico. Barcelona: Ariel.

Alcaraz, Enrique, Campos, Miguel Ángel y Giambruno, Cynthia (2002): El inglés jurídico norteamericano. Barcelona: Ariel.

Andrades Moreno, Arsenio (2014): Estudio contrastivo de unidades fraseológicas especializadas (UFE) en un corpus comparable bilingüe de contratos de derecho civil en lengua inglesa y española. Tesis Doctoral, inédita. Madrid: UCM.

Arellano, Pablo y Díaz, Lourdes (2008): Proyectos pedagógicos de aula: estructura textual y mecanismos de cohesión. Opción. 56:124-142.

Barceló Martínez, Tanagua (2010): La polisemia y la (no)sinonimia en el proceso de enseñanza-aprendizaje del lenguaje jurídico. Anales de Filología Francesa. 18:29-44.

Bestué, Carmen y Orozco, Mariana (2011): La necesidad de la naturalidad en la reformulación en la traducción jurídica en la 'era de la automatización' de las traducciones. Jostrans. 15:180-199.

Bhatia, Vijay Kumar (1993): Analysing Genre: Legal Language Use in Professional Settings. Londres: Longman.

Biber, Douglas (1990): Methodological issues regarding corpus-based analyses of linguistic variation. Literary and Linguistic Computing. 5(4):257-269.

Borja, Anabel (2000): El texto jurídico inglés y su traducción al español. Barcelona: Ariel.

Bondarko, Alexander V. (1990): Functional Grammar: A Field Approach. Ámsterdam/Filadelfia: John Benjamins.

Botley, Simon y McEnery Tony, eds. (2000): Corpus-based and Computational Approaches to Discourse Anaphora. Ámsterdam/Filadelfia: Johns Benjamin.

Casas Gómez, Miguel (1995): Sinonimia y eufemismo. Quaderni di Semántica. 16:17-46.

Chesterman, Andrew (1998): Contrastive Functional Analysis. Ámsterdam/Filadelfia: John Benjamins.

Chromá, Marta (2011): Synoymy and Polysemy in Legal Terminology and Their Applications to Bilingual and Bijural Translation. Research in Language. 9(1):31-50.

Diez, María Ángeles (2009): Análisis contrastivo inglés-español de las crónicas futbolísticas en la prensa escrita. De la descripción a las aplicaciones. Tesis Doctoral, inédita. Valladolid: Universidad de Valladolid.

Engberg, Jan (2002): Legal Meaning Assumptions - What Are The Consequences For Legal Interpretation And Legal Translation? International Journal for the Semiotics of Law. 15:375388.

EngBerg, Jan (2017): Developing an Integrative Approach for Accessing Comparative Legal Knowledge for Translation. Revista de Llengua i Dret/Journal of Language and Law. 68:5-18.

Ferran, Elena (2004): El literalismo en la traducción de documentos jurídicos: una vía para su solución. LSP \& Professional Communication. 4(2):27-37.

Ferrari, Laura (2002): ¿Un caso de polisemia en el discurso jurídico? Terminology. 8(2):221-244. 
Freixa, Judit, Fernández-silva, Sabela y Cabré, María Teresa (2008): La multiplicité des chemins dénominatifs. Meta. 53:731-747.

García-Hernández, Benjamín (1997): Sinonimia y diferencia de significado. Revista Española de Lingüistica. 27(1):1-31.

GonzÁlez, José Antonio (2014): Elementos anafóricos en las sentencias actuales: los adjetivos deverbales de participio. Revista de Llengua i Dret/Journal of Language and Law. 62:23-34.

GoźDź-Roszkowski, Stanisław (2011): Patterns of Linguistic Variation in American Legal English. A Corpus-Based Study. Frankfurt am Main: Peter Lang.

GoźDź-Roszkowski, Stanisław (2013): Exploring near-synonymous terms in legal language. A corpus-based, phraseological perspective. In: Lucja BIEL y Jan ENGBERG, eds. Research Models and Methods in Legal Translation. Linguistica Antverpiensia. 12:94-109.

Halliday, Michael A. K. y Hasan, Ruqaiya (1976): Cohesion in English. Londres: Longman. Hernando Cuadrado, Luis Alberto (2003): El lenguaje jurídico. Madrid: Editorial Verbum.

IzQuierdo, Marlén (2012): Estudio contrastivo y de traducción inglés-español: Construcciones de -ing inglesas y sus equivalentes en español. Tesis doctoral, inédita. León: Universidad de León.

Lyons, John (1995): Linguistic Semantics: An Introduction. Cambridge: Cambridge University Press.

Marimón, Carmen (2008): Análisis de textos en español. Teoría y práctica. Alicante: Publicaciones de la Universidad de Alicante.

Mayoral, Roberto (2004): Lenguajes de especialidad y traducción especializada. La traducción jurídica. In: Consuelo Gonzalo García y Valentín García Yebra, eds. Manual de documentación y terminología para la traducción especializada. Madrid: Arcos Libros, 49-72.

Mayoral, Roberto (2007): Comparación de los contratos en inglés y en español como ayuda al traductor. Papers Lextra. 3:55-61.

Moreno Pérez, Leticia (2017): The Management of Documentation Resources in Specialised Translation Trainees: a Case Study on Legal Translation. Entreculturas. 9:291-301.

Murphy, M. Lynne (2003): Semantic Relations and the Lexicon. Cambridge: Cambridge University Press.

OrTs Llopis, María Ángeles (2005): Semejanzas y diferencias léxicas en el lenguaje contractual en inglés y en castellano. Ibérica. 10:23-40.

Pontrandolfo, Gianluca (2013): Polisemia y sinonimia en la terminología del derecho procesal penal español e italiano: el caso de «sumario»/«indagini preliminari». Revista de Llengua i Dret/Journal of Language and Law. 60:37-49.

RABADÁn, Rosa (2002): Análisis contrastivo y traducción especializada inglés-español: el programa ACTRES. In: José María Bravo Gonzalo, ed. Nuevas perspectivas de los estudios de traducción. Valladolid: Universidad de Valladolid, 35-56.

Rabadán, Rosa y Fernández, Purificación (2002): La traducción inglés-español: fundamentos, herramientas, aplicaciones. León: Universidad de León.

Regueiro Rodríguez, María Luisa (2010): La sinonimia. Madrid: Arco Libros.

Román Mínguez, Verónica (2012): Acquiring Competencies in Economic-Financial Translation: from the Classroom to the Marketplace. Revista Alicantina de Estudios Ingleses. 25:387-400.

SAger, Juan (1990): A Practical Course in Terminology Processing. Ámsterdam/Filadelfia: John Benjamins.

ŠARČEviĆ, Susan (1991): Bilingual and Multilingual Legal Dictionaries: New Standards for the Future. Meta. 36(4):615-626.

SuÁrez, María Mercedes (2004): Análisis contrastivo de la variación denominativa en textos especializados: del texto original al texto meta. Tesis doctoral, inédita. Barcelona: Universidad Pompeu Fabra.

Thiry, Bernard (2009a): La sinonimia nocional, un caso peculiar de sinonimia en terminología. Entreculturas. 1:219-257.

Thiry, Bernard (2009b): La motivación de los términos en terminología jurídica. Cómo la terminología jurídica asume los riesgos de su evolución. Revista de Llengua i Dret/Journal of Language and Law. 51:161-185.

Tiersma, Peter M. (1999): Legal Languages. Chicago: University of Chicago Press. 